Relations industrielles

Industrial Relations

\title{
Restrictions à la liberté syndicale
}

La Loi Taft-Hartley

\section{Gérard Tremblay}

Volume 3, numéro 1, septembre 1947

URI : https://id.erudit.org/iderudit/1023555ar

DOI : https://doi.org/10.7202/1023555ar

Aller au sommaire du numéro

\section{Éditeur(s)}

Département des relations industrielles de l’Université Laval

\section{ISSN}

0034-379X (imprimé)

1703-8138 (numérique)

Découvrir la revue

\section{Citer cet article}

Tremblay, G. (1947). Restrictions à la liberté syndicale : la Loi Taft-Hartley.

Relations industrielles / Industrial Relations, 3(1), 2-4.

https://doi.org/10.7202/1023555ar

Tous droits réservés @ Département des relations industrielles de l’Université Laval, 1947
Ce document est protégé par la loi sur le droit d'auteur. L'utilisation des services d'Érudit (y compris la reproduction) est assujettie à sa politique d'utilisation que vous pouvez consulter en ligne.

https://apropos.erudit.org/fr/usagers/politique-dutilisation/ 


\section{Bulletin des relations in \\ Volume 3, numéro 1 \\ publié par \\ le Département des relations industrielles de Laval.}

T.R.P. Georges-H. LÉvesque, o.p., doyen. Gérard Tremblay, directeur.

J. O'CONNELL-MAHER, assistant-directeur.

Abbé Gérard Dion, secrétaire.

Charles BÉlanger et Jean Gagne, assistantssecrétaires.

\section{ABONNEMENT:}

Etranger \$2.00

Adressez toute correspondance au Secrétaire

Département des relations industrielles, Faculté des sciences sociales, Université Laval, Québec, P.Q.
Canada $\$ 1.50$

Le numéro $\$ 0.20$

\section{SOMMAIRE}

Une troisième année

La Direction.

page

La Loi Taft-Hartley

Gérard Tremblay.. $\quad . . \quad$..

Augmentation de salaire et hausse de prix

Gérard Dron..

Stabilité ouvrière et distributisme social

Gonzalve Pounn, o.f.m...

Le catholicisme social face aux grands courants contemporains. Lettre de

Pie XII à Charles Flory.. .. .. .. ..

The Taft-Hartley Act

Gérard Tremblay..

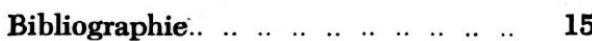

Our third year

The EdrTors.
1

2 5 8

\section{RESTRICTIONS A LA LIBERTE SYNDICALE'}

\section{LA LOI TAFT-HARTLEY}

\section{Gérard TREMBLAY}

La loi américaine Taft-Hartley, amendant le National Labor Relations Act de 1935, est entrée en vigueur le 22 août dernier, soit soixante jours après son approbation par le Sénat, renversant par un vote des deux-tiers de ses membres, à l'exemple de la Chambre des représentants, le veto du président Truman.

On sait la campagne formidable de la Fédération américaine du Travail contre le bill avant son adoption. Radio, publicité de la presse, assemblées publiques, parades, rien n'a été épargné par les adversaires du bill. La F.A.T. a consacré un million et demi à cette campagne. Le C.I.O. n'a pas manqué non plus de combattre vigoureusement une loi restrictive des privilèges des syndicats ouvriers.

Quelle sera l'attitude des grandes centrales ouvrières maintenant que le bill Taft-Hartley est la loi du pays ? Il semble qu'elles tenteront de continuer la lutte par tous les moyens. Le premier est de boycotter la loi en s'abstenant de demander la certification d'agents-négociateurs au National Labor Relations Board et de tenter la négociation collective dans le cadre de la liberté. Mais les employeurs peuvent alors refuser de négocier légalement. Un deuxième moyen est d'in- troduire dans les contrats collectifs des clauses libérant les syndicats ouvriers de certaines obligations. En troisième lieu, des unions songent à cesser de signer des accords et à ne présenter aux employeurs qu'un mémoire de leurs revendications. Il reste que le problème demeure entier pour le moment. Les rivalités de juridiction syndicale ne pouvant être réglées que par un tribunal comme le N.L.R.B., il faudra bien que les unións recourent à ses bons offices si elles veulent trouver une solution à ce genre de conflits.

Quelles sont donc les principales restrictions à la liberté syndicale prévues par la loi Taft-Hartley?

$1^{\circ}$ L'atelier d'union est règlementé. $2^{\circ}$ Les unions peuvent introduire une action civile contre les employeurs mais ceux-ci peuvent aussi poursuivre les unions coupables de bris de contrat. $3^{\circ}$ Les unions ne peuvent bénéficier de la Loi nationale de relations ouvrières si elles ne font pas préalablement certains rapports au Secrétaire du Travail. $4^{0}$ Les unions à direction communiste ou affiliées à une fédération qui la tolère ne peuvent se prévaloir de la loi. $5^{0}$ Les grèves d'importance nationale sont soumises à des restrictions. Il est intéressant de demander au texte législatif quelques précisions sur ces restrictions. 
$1^{\circ}$ Règlementation de latelier d'union. L'article 7 de la loi consacre le droit d'organisation ouvrière mais elle précise «que les travailleurs auront le droit de s'abstenir de toutes ou de quelques-unes des activités syndicales, tant que ce droit n'est pas affecté par un contrat collectif obligeant à l'affiliation syndicale comme condition d'emploi selon la section 8 (a) (3).» Or, cette section défend à un employeur non seulement d'empêcher un salarié d'appartenir à une union, mais de faire exception entre syndiqués et non syndiqués «sous réserve qu'il pourra signer un accord prévoyant que ses salariés devront appartenir à une union dans les trente jours de leur entrée au travail; sous réserve que la dite union aura été certifiée comme agent négociateur; sous réserve que par voie de scrutin la Commission de relations ouvrières se sera rendu compte que cinquante pour cent des ouvriers intéressés sont favorables à un contrat d'union; sous réserve encore que l'employeur ne sera pas taxé de pratique interdite s'il garde un ouvrier que l'union refuse d'admettre dans ses rangs selon les conditions ordinaires; sous réserve enfin que l'affiliation syndicale ne sera pas refusée à un ouvrier pour une autre raison que celle de ne pas payer ses con tributions ou sa taxe d'entrée.»

On le voit l'atelier fermé est pratiquement prohibé. L'atelier d'union est permis pourvu que la majorité des ouvriers le requière. Il n'a d'effet pour un ouvrier qu'après trente jours de travail à l'usine. L'union doit être certifiée; de plus, elle ne peut faire congédier un membre récalcitrant s'il paie ses cotisations, ni lui imposer de conditions d'entrée anormales.

$2^{\circ}$ Responsabilité civile des unions. Le titre III, section 301 de la loi règlemente les poursuites instituées par ou contre les organisations ouvrières. Même si l'union n'est pas incorporée selon une loi statutaire, elle est néanmoins considérée comme une entité juridique pouvant ester en justice. C'est une réforme radicale imposée au syndicalisme américain qui a toujours refusé l'incorporation dans la crainte que des procédures d'injonction soient prises contre les unions.

L'article 301 se lit comme suit : «a) Des poursuites en violation de contrat entre un employeur et une union ouvrière représentant les salariés dans une industrie affectant le commerce tel que défini dans cette loi, ou entre unions ouvrières, peuvent être instituées dans toute cour de district des Etats-Unis ayant juridiction sur les parties, sans égard au montant en litige ou à la citoyenneté des parties. »

«b) Toute organisation ouvrière qui représente les salariés dans une industrie affectant le commerce tel que défini dans cette loi et tout employeur qui exerce des activités affectant le commerce tel que défini dans cete loi seront liés par les actes de leurs agents. Toute organisation ouvrière peut poursuivre ou être poursuivie comme une entité et au nom des salariés qu'elle représente, devant les cours américaines. Toute décision judiciaire en matière d'argent rendue contre un syndicat par une cour de district des EtatsUnis, sera exécutoire contre le syndicat seulement et son actif et ne sera pas exécutoire contre tout individu membre ou ses biens personnels.

$3^{0}$ Rapports au Secrétaire du Travail. Si une union veut obtenir le privilège d'agent négociateur, si elle veut établir l'atelier d'union, si elle veut que ses plaintes contre un employeur au sujet des pratiques interdites soient reçues par le Board, elle doit elle-même de même que l'union nationale ou internationale à laquelle elle est affiliée, déposer ses constitutions et règlements chez le Secrétaire du Travail et faire un rapport indiquant :

a) le nom de l'union et l'adresse de sa place d'affaires principale;

b) les noms, titres, compensations et allocations de ses trois principaux officiers et de tout autre officier ou agent ayant reçu $\$ 5,000$ ou plus durant l'année précédente et le montant réel reçu par les dits officiers durant cette année;

c) la façon dont ces officiers ou agents ont été élus, nommés ou choisis ;

d) le montant de la taxe d'entrée et des cotisations exigibles;

e) la procédure relative à la qualification des membres et à toutes restriction à ce sujet; à l'élection des officiers et des représentants d'atelier; à la convocation des assemblées spéciales et régulières; aux cotisations spéciales, à l'imposition des amendes; à l'autorisation de négocier les revendications; à la ratification des conventions; à l'autorisation des grèves; à la dépense des fonds syndicaux; à l'audition des transactions financières; à la participation à des plans d'assurances ou de bénéfices; à l'expulsion des membres et des motifs évoqués.

L'union doit également présenter au Secrétaire du Travail un rapport sur l'état des recettes et leurs sources; sur l'actif et le passif à la fin de l'année; sur les dépenses et leurs raisons. L'union doit enfin présenter à ses membres un rapport financier similaire. Cette obligation de rapporter se renouvelle chaque année.

$4^{\circ}$ Mise au ban des communistes. L'article 9 (h) prive des avantages de la Loi nationale des 
relations ouvrières toute union locale dont les officiers n'ont pas produit devant le « Board » un affidavit attestant qu'ils ne sont pas membres du parti communiste. La même obligation est imposée aux officiers de la centrale nationale ou internationale à laquelle est affiliée l'union locale. Les officiers doivent aussi déclarer dans l'affidavit qu'ils n'adhèrent ni ne donnent appui à une organisation qui favorise le renversement du gouvernement des Etats-Unis par la violence ou toute autre méthode illégale ou inconstitutionnelle.

$5^{\circ}$ Limitation du droit de grève. La loi n'interdit pas la grève de façon générale. Précisément l'article 13 détermine que «rien dans la présente loi, sauf s'il y est prévu spécifiquement, ne doit être interprété comme empêchant, limitant ou diminuant le droit de grève ».

Or, il est spécifiquement prévu au Titre II, section 206, que «si, dans l'opinion du Président des Etats-Unis, une grève ou un lock-out ou une menace de grève ou de lock-out dans une industrie ou une partie importante de celle-ci s'occupant de commerce, transport, transmission ou communication entre états ou avec des nations étrangères ou s'occupant de produire des marchandises pour fin de commerce, peut, s'il éclate ou continue, mettre en péril la santé ou la sécurité nationale, celui-ci (le Président) peut nommer une commission d'enquête sur les faits du différend qui lui présentera un rapport dans les délais indiqués.» Sur réception du rapport, le Président peut ordonner au Procureur général de requérir un bref d'injonction d'une cour de district fédérale contre les tenants de la grève et du lock-out. Si le bref est accordé, les parties devront s'efforcer de régler le litige avec le concours du service de conciliation fédéral; soixante jours après l'émission du bref d'injonction le président reconvoquera la commission d'enquête qui fera rapport sur les faits et les positions des parties, après la conciliation et la médiation. Ce rapport sera rendu public. Dans les quinze jours qui suivront, le Conseil national des relations ouvrières tiendra un scrutin auprès des ouvriers de chaque employeur afin de leur permettre d'accepter ou de refuser l'offre finale de règlement présentée par tel employeur. Le Procureur général sera avisé dans les cinq jours du résultat du vote par le Conseil des relations ouvrières. Le Procureur général fera lever alors l'injonction. A son tour le Président rapportera au Congrès sur toute l'affaire et fera les recommandations jugées opportunes.

Comme nous l'avons dit plus haut, la seule restriction au droit de grève doit être motivée par l'urgence nationale. Par ailleurs, l'article 201 précise que la politique américaine est de faire la conciliation de tous les conflits du travail par voie de conférences et de négociations collectives; cette politique met à la disposition des parties un service de conciliation pour les aider à prévenir les conflits de droit et d'intérêt, les invite à insérer dans les contrats de travail des clauses de règlement des griefs, d'avis de dénonciation et de modification des accords. Conciliation, médiation, arbitrage volontaire sont recommandés. Nulle part cependant n'est imposé l'arbitrage à sentence exécutoire comme on le connaît dans notre province du fait de la Loi des différends entre les services publics et leurs salariés.

Nous avons résumé les principales restrictions apportées au syndicalisme américain par la Loi Haft-Hartley. Il n'y a rien dans le cadre strict des principes que l'on puisse réprouver dans cette législation. Celle-ci est-elle opportune chez nos voisins ? C'est là une question que nous laissons sans réponse. On verra comment la loi s'appliquera.

Dans une dépêche de la Presse Associée, de Washington, donnant sur cette loi l'opinion du Département d'Action sociale de la National Catholic Welfare Conference, à l'occasion de la Fête du Travail, la N.C.W.C. exprime l'espoir que le travail corrigera volontairement les abus spécifiques que la loi en premier lieu a eu pour but d'éliminer et presse fortement ouvriers et patrons de se rencontrer dans un effort sincère et cordial pour corriger les conséquences de la mise en vigueur des dispositions non satisfaisantes de la loi. 